\title{
LA POBLACIÓN DE ALICANTE: DINÁMICA, ESTRUCTURA SOCIAL Y REPERCUSIONES TERRITORIALES ${ }^{1}$

\author{
Vicente Gozálvez Pérez
}

\begin{abstract}
RESUMEN
El estudio resalta las favorables perspectivas para la evolución demográfica de la ciudad de Alicante, pues sus funciones terciarias y capitalinas jerarquizan una pujante y densa región urbana, formada esencialmente por la franja litoral, dominada por actividades terciarias, y el corredor industrial junto al río Vinalopó. No obstante, la ciudad ya experimenta dificultades de crecimiento demográfico, derivados tanto de la caída de nacimientos como de la reducción del saldo migratorio positivo, mientras a corto plazo se espera un notable envejecimiento causado tanto por la evolución de la estructura por edades como por la actual inmigración de adultos y jubilados. Es necesario definir con más precisión la vocación económica futura de la ciudad, clave sobre la que se apoyará un crecimiento demográfico diferenciado.

\section{RÉSUMÉ}

L'étude met en valeur les favorables perspectives pour l'avenir démographique de la ville d'Alicante, car ses foctions tertiaires et de capital sont au sommet d'une région urbaine dinamique et très peuplée, formée par la frange littoral tertiaire et le couloir industriel parallèle au fleuve Vinalopó. Cependant, la ville commence à être soumise aux difficultés d'augmentation démographique à cause de la chute des naissances et de la réduction du solde migratoire positive; de même dans l'avenir il y aura un vieillissement important derivé de l'evolution de la structure des âges et de l'inmigration d'adultes et de retraités. Il faut définir avec plus d'énergie l'avenir économique de la ville, clé pour son futur développement démographique.
\end{abstract}

La temática objeto de esta mesa redonda se enmarca en
el título general del ciclo «Alicante una ciudad hacia el futuro», es
decir en el análisis de la situación demográfica actual así como de
las perspectivas de futuro, pero también con referencias al pasado
más cercano, pues los cambios de tendencia en las diversas
variables demográficas han sido muy importantes después de 1960.
Es precisamente durante los últimos treinta años cuando

\footnotetext{
${ }^{1}$ Texto de la conferencia pronunciada el día 16 de noviembre de 1989, dentro del ciclo «Alicante, una ciudad hacia el futuro», desarrollado con motivo del Quinto Centenario de la Ciudad de Alicante.
} 
se modifican sustancialmente las anteriores trayectorias económicas y demográficas de Alicante y su área urbana, y se origina mediante varios cambios y pulsaciones la situación actual, que es, sin duda, con la que se ha de proyectar la ciudad a corto y medio plazo.

El estudio de las situaciones en los tres momentos indicados, sin duda requiere referencias a varias escalas: la ciudad, tanto en su conjunto como en sus barrios, área metropolitana y región urbana, en tanto estos espacios exteriores a la ciudad de Alicante quedan jerarquizados por ella. Es decir la ciudad central, por las características de sus funciones de capital, tanto administrativa como económica, tiene desarrollo actual y futuro en buena parte como centro de una región urbana con la que establece relaciones económicas y funcionales cada vez más intensas e interdependientes.

Los estudios sobre la población de Alicante con finalidad aplicada y de previsión, tienen dos escalas de análisis privilegiadas, que a su vez se complementan, pues la planificación se ha de realizar tanto para las diversas partes o barrios del espacio urbano compacto, como para la evolución del conjunto de la ciudad, muy dependiente -al desempeñar funciones de capital- de los espacios o núcleos que por ella quedan jerarquizados. Así, en la primera escala de estudio, la de barrios o espacios intraurbanos, las situaciones sociodemográficas son tan diferentes y en ocasiones opuestas que pueden recordar las que se dan entre países del Tercer Mundo y los más desarrollados, tal como ha quedado manifiesto en un reciente estudio sobre la ciudad (Gozálvez, V. y otros, 1987, a). Es evidente que con estas diferencias entre barrios, la planificación precisa de informaciones ajustadas sobre cada uno de ellos; sin duda es necesario potenciar estos estudios básicos, para así poder actuar del modo más adecuado sobre las distintas partes de la ciudad, teniendo en cuenta además que el conjunto urbano tiene estructura de verdadero tejido, interdependiente, pues ningún barrio tiene su razón de ser sólo dentro de sus límites, sino que la ciudad funciona como un todo, pero con necesidades, posibilidades y finalidades específicas en sus distintos espacios.

La segunda escala a la que han de atender los estudios de población como base de planificación, es el conjunto de la ciudad y de la región o área urbana en la que aquella se sitúa, sobre todo, como es el caso de Alicante, si esa ciudad desempeña funciones económicas, culturales, sanitarias, etc., para una población residente fuera de su espacio urbanizado continuo, y además, como se ha expresado en repetidas ocasiones, si se pretende potenciar sustancialmente esas actividades especializadas ante la demanda de su dinámica y densa región urbana, así como de otras poblaciones más alejadas.

Los estudios geodemográficos para planificaciones en las dos escalas indicadas se hacen especialmente necesarios en el caso de Alicante, pues la ciudad continúa teniendo notable dinamismo en ambas dimensiones. El análisis intraurbano no será abordado ahora, pues además de haber sido objeto de una reciente publicación, el tratamiento global está más directamente conectado con la finalidad que persiguen las actividades ahora programadas con motivo del $\mathrm{V}$ Centenario de la ciudad de Alicante.

\section{La ciudad de Alicante en la confluencia de dos ejes demográficos: el desarrollado en la franja litoral, dominado por actividades terciarias, y el constituido junto al río Vinalopó, especializado en la industria}

La ciudad de Alicante así como la región urbana en torno a ella se han constituido durante el último tercio de siglo en un espacio de gran crecimiento demográfico y de marcado carácter urbano, tanto por el tamaño de los núcleos como por sus especializaciones en actividades secundarias -valle del Vinalopó- y terciarias -eje litoral-, tal como 
ampliaremos en el epígrafe siguiente. Contemplado este espacio a nivel de País Valenciano, es el que presenta la mayor vitalidad relativa, tanto en las cifras de crecimiento vegetativo -diferencia entre nacimientos y defunciones- como en saldo migratorio, y por tanto en la resultante de ambos, el crecimiento censal.

Así, entre 1961 y 1985 el crecimiento vegetativo alcanzó en la provincia de Alicante 255.072 habitantes, a los que se suman otros 287.906 como saldo migratorio neto, es decir durante el período indicado ambos componentes del crecimiento censal provocaron un aumento del $61 \%$ sobre la población existente en 1960. En igual período la provincia de Valencia ganaba 398.460 habitantes como saldo vegetativo y 251.594 como saldo migratorio, que equivalen a un aumento del 45\% sobre el censo de 1960; en Castellón las ganancias respectivas son 53.357 como crecimiento natural y 44.734 como crecimiento migratorio, cuya suma equivale a un aumento del $30 \%$ sobre la población censada en 1960. Hay pues notables diferencias en la vitalidad demográfica de las provincias valencianas, con máximo en Alicante y mínimo en Castellón. Además, las diferencias se acrecientan si la comparación se hace sólo con el saldo migratorio, pues el acumulado entre 1961 y 1985 equivale en la provincia de Alicante al 40\% del censo de 1960, mientras tal porcentaje es del $18 \%$ en la de Valencia y del 13\% en la de Castellón; si nos referimos sólo a las ganancias del movimiento natural acumulado entre 1961-85 sobre la población de 1960, estas equivalen al 35'8\% en la provincia de Alicante, al 27'9\% en la de Valencia y al 15 '7\% en la de Castellón.

La evolución censal de los municipios survalencianos entre 1960 y 1986, se sintetiza en tres períodos con comportamientos diferentes: a) la década de 1961-1970 se caracteriza por cambios censales fuertes, unos municipios se vacían mientras otros crecen con gran celeridad, originándose situaciones fuertemente opuestas incluso en municipios vecinos. Los mayores aumentos censales se apoyan en la industria, en el turismo litoral y en las funciones propias de la capital provincial, mientras las áreas agrícolas, incluso las de regadío intensivo (Bajo Segura), experimentan descensos de población o estancamiento en el mejor de los casos. b) Entre 1976 y 1981, tanto el proceso de crecimiento como el de despoblación se suavizan considerablemente, pues la crisis económica, especialmente industrial, ha reducido o incluso paralizado los grandes aportes inmigratorios de los años 1960-75. En contraposición, las zonas agrícolas con posibilidades agrarias que en 1961-70 perdieron población (Bajo Segura), ahora acrecientan sus censos o aminoran la despoblación ante la falta de empleos en los centros industriales. Sólo en las áreas montañosas y aisladas persisten altas tasas de despoblación. c) Durante el último intercensal, 1981-86, los contrastes en los crecimientos censales, positivos o negativos, han desaparecido, pues los censos sólo suelen variar en las cifras que proporcionan los excedentes demográficos naturales, escasos ya que la natalidad se ha reducido fuertemente. Ahora son pocos los municipios que mantienen variaciones censales extremas; sólo los del litoral, con fuerte desarrollo turístico, mantienen en 1981-86 aumentos censales superiores al 2-3\% anual, con extremos en Alfas del Pi con 6'7\%, Calpe 5'1\%, Guardamar del Segura 3'6\%, Jávea 3'7\%, Torrevieja 10'0\% y Benidorm con un discutido 31'8\% anual. Las ciudades grandes del País Valenciano sólo consiguen, en el último intercensal, crecimientos que en ocasiones ni siquiera retienen sus saldos vegetativos: así Elche aumenta 1'3\% anual, cuando en 1961-70 creció un 6'7\% anual y 2\% en 1976-81; Alicante crece un $11^{\prime} 1 \%$ en 1981-86, frente a 5'2\% en 1961-70 y 2'8\% en 1976-81. Pese a esta drástica disminución del crecimiento demográfico de Alicante y Elche, ambas ciudades mantienen mayor vitalidad que Castellón -con 0'5\% en 1981-86- y sobre todo más que Valencia que en 1981-86 ha disminuido su censo demográfico en 15.329 habitantes de derecho mientras su área metropolitana también está demográficamente paralizada o en disminución, con las únicas 


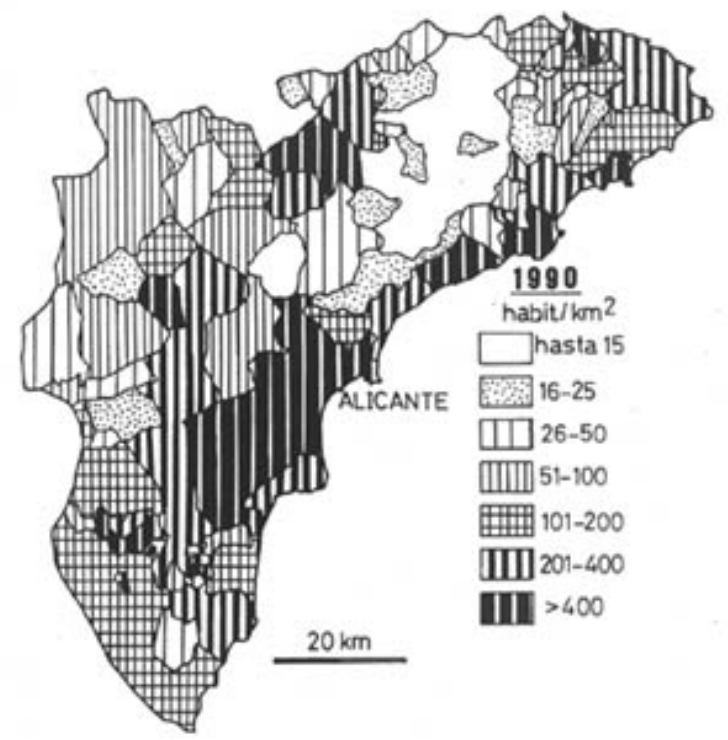

FIGURA 1. Provincia de Alicante. Densidad demográfica en 1990. Habitantes por kilómetro cuadrado, a escala municipal.

excepciones de La Eliana -residencial- y Almusafes -industria automovilística-.

Al comparar los dos últimos quinquenios, vemos que los aumentos censales de 1981-86, en el mejor de los casos, se han reducido a la mitad de los experimentados en 1975-81, ya en declive: así el censo de Alicante capital creció el 11'4\% en 1975-81, y el 5'6\% en 1981-86; el área metropolitana de Alicante en los mismos años tuvo aumentos del 20'9\% y 10'1\%, mientras en Elche fueron de 10'3\% y 6'5\%, respectivamente.

Ahora bien, al señalar las cifras de aumentos censales, una cuestión fundamental respecto a la evolución futura, es saber si esos crecimientos son producto de movimientos de inmigración o de movimiento natural, ya que el significado económico y demográfico de estos es bien distinto.

En la ciudad de Alicante, como en la mayoría de las capitales españolas, tanto el movimiento natural como el migratorio han experimentado disminuciones sustanciales durante el último quinquenio respecto al anterior: así en 1976-80 el saldo vegetativo fue de 13.674 habitantes y de 6.702 en 1981-85, mientras el saldo migratorio (balance entre entradas y salidas) ha evolucionado de 18.160 a 7.454 habitantes. Esta tendencia negativa afecta igualmente a casi toda el área metropolitana de la capital (el Campello, Mutxamel, 


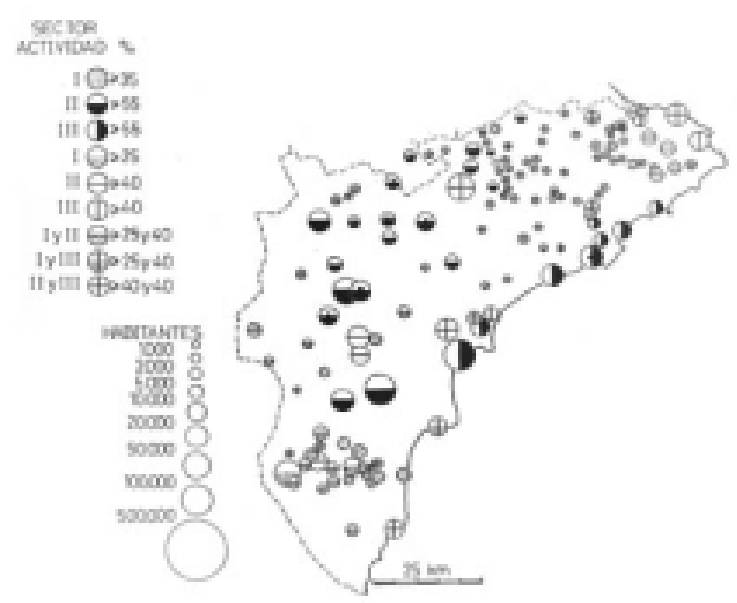

FIGURA 2. Provincia de Alicante. Sectores de actividad predominantes en los municipios. Año 1981. Los puntos gruesos en el centro del círculo indican porcentajes superiores al 55\% en el sector I, y superiores al $70 \%$ en el II y III.

Sant Joan y Sant Vicent), aunque con disminuciones relativas algo más atenuadas: el saldo vegetativo fue de 2.347 habitantes en $1976-80$ y de 1.255 en 1981-85, mientras el saldo migratorio daba en los mismos períodos 6.367 y 3.863 habitantes, respectivamente.

En el caso de Elche la evolución reciente de ambos componentes del crecimiento demográfico es igualmente de contracción, pero con características bien distintas a las de la capital y su área metropolitana: es decir el saldo vegetativo de Elche ha disminuido sólo un 23\% entre ambos quinquenios, frente a un $51 \%$ en la capital y a un $47 \%$ en los municipios del área metropolitana; en cambio el saldo migratorio se redujo en la capital un 59\%, un 39\% en el área metropolitana y en Elche prácticamente ha desaparecido. En suma, si repartimos el crecimiento censal entre ambos saldos, vegetativo y migratorio, en la capital la inmigración supone más de la mitad del crecimiento en ambos quinquenios; en el área metropolitana la inmigración aporta las tres cuartas partes del aumento censal en cada quinquenio; en Elche el crecimiento migratorio sólo aporta el $12 \%$ del crecimiento censal en 1975-80 y el 1\% en 1981-85.

Si la inmigración, aunque en fuerte descenso, continúa siendo la parte decisiva en el 
crecimiento de Alicante y su área metropolitana, se debe por una parte al atractivo residencial de la zona para la población del centro y norte de la península, y por otra a las funciones de capital, a la creación de empleo terciario, que es el que, a su vez permite, en alto grado, el funcionamiento del área metropolitana como dormitorio de la capital. La creación de empleo terciario responde, sin duda, a las demandas con origen en la densa región urbana que centra y jerarquiza Alicante capital. Por el contrario, la especialización industrial de Elche -el 59\% de sus activos son secundarios en 1981- y la crisis reciente de este sector, explican el comportamiento demográfico de este municipio -que ejemplifica a los del corredor del Vinalopó- tanto en la desaparición de su saldo migratorio positivo como del aún saneado saldo natural, ya que el fuerte aumento demográfico requerido por el desarrollo de su industria entre 1960 y 1975 se hizo con inmigración joven y natalista (en 1986 aún residen en Elche 33.444 inmigrados de Andalucía, Murcia y Castilla-La Mancha, a los que hay que añadir más de 12.000 del Bajo Segura). Así pues, es evidente que las características y posibilidades de crecimiento demográfico, a escala de municipios y áreas reducidas, tienen actualmente una decisiva conexión con las características económicas de esos mismos espacios. Las distintas estructuras económicas son las responsables del diferente ritmo demográfico que experimentan los espacios del sur de la Comunidad Valenciana: las áreas industriales han perdido toda su capacidad de inmigración, tan decisiva en los años 1960-75, mientras las áreas terciarias mantienen cierta vitalidad inmigratoria. El movimiento natural tiende a tener un comportamiento opuesto: los municipios terciarios, y fundamentalmente los litorales, han disminuido su saldo natural reciente más que en las áreas industriales.

En resumen, durante la última década los municipios industriales survalencianos crecen sólo por movimiento natural, mientras la inmigración ha desaparecido o es de signo negativo, en fuerte contraste con el período 1960-1975. Los municipios terciarios también aminoran drásticamente su crecimiento respecto a 1960-75, pero aquí el escaso crecimiento se reparte entre aportes inmigratorios y aportes naturales; en la capital ambos están equilibrados, pero al acentuarse la función turístico-residencial el aporte inmigratorio gana peso específico y el natural lo disminuye, pues mientras la atracción inmigratoria está directamente conectada con la economía, el crecimiento natural, que sólo depende de la natalidad ya que la mortalidad se mantiene estable, depende cada vez más de factores culturales. Es fundamental, pues, saber qué economía se va a prever en la capital y su entorno, para así prever las posibilidades de crecimiento demográfico, aunque evidentemente el aumento del espacio urbano no es estrictamente parejo al demográfico, pues el mismo número de habitantes necesita cada vez más espacio urbanizado, de acuerdo con las nuevas características de las estructuras comerciales, de circulación, de espacios residenciales, etc.

\section{Acusadas especializaciones en la población activa de la región urbana de Alicante}

El conocimiento de la población activa, y sobre todo de su distribución en las distintas ramas y subsectores de actividad, es actualmente un adecuado índice del desarrollo económico, es decir, del elemento más decisivo de diferenciación entre las distintas comunidades. El conocimiento de la estructura profesional es asimismo esencial para calibrar o prever aspectos hoy tan decisivos como, entre otros, los que afectan a la seguridad social, jubilaciones, posibilidades de ahorro, nivel socioeconómico, etc.

Sin embargo las estadísticas oficiales españolas de población activa tienen incluso en la actualidad, notables limitaciones sobre todo en las informaciones espaciales, especialmente 
en las referidas a escalas más detalladas que la provincia. Sólo el censo de población de 1981 ha constituido una excepción en la historia estadística de España, ya que ofrece cifras relativas -aunque no absolutas- de la población ocupada en las principales ramas de actividad para todos los municipios; sin embargo, esta información fue suprimida en el padrón de habitantes de 1986, hecho negativo que confiamos sea subsanado en el próximo padrón y censo de 1991 ya que, además de encontrarnos en período de cambios sustanciales en el empleo de muchos subsectores significativos de actividad, aquellos son la única fuente de cobertura nacional con esta información a escala municipal.

El mapa municipal que cartografía los sectores de actividad en 1981, destaca el sector-es con mayor proporción de empleos junto con su tamaño demográfico. El sector primario es el preponderante en casi todos los municipios rurales o menores de 2.000 habitantes, con porcentajes de sus activos incluso superiores al 55-60\% en la mayoría de los municipios de la Montaña, aunque estas cifras relativas afectan a muy escasa población absoluta. La población activa agraria también alcanza rango de especialización -más del 35 o 25\% de los activos- en muchos municipios del Bajo Segura, donde los de tamaño demográfico intermedio son numerosos; no obstante, la especialización agrícola de esta comarca con frecuencia es compartida con altos porcentajes de activos secundarios, con peso de los dedicados a la construcción.

El eje del río Vinalopó queda caracterizado por su especialización industrial, con porcentajes de sus activos superiores al 55\%; aquí destacan las industrias del calzado, y además con núcleos de gran volumen de empleo, como Elche y Elda-Petrer. Esta zona industrial del Vinalopó se prolonga hacia el interior por las sucesivamente contiguas comarcas de la Foia de Castalla, con industrias del juguete, y Valles de Alcoy, donde las industrias textiles se implantaron, como su mayor especialización, ya desde la segunda mitad del siglo XVIII; en bastantes municipios de estas áreas industriales, el sector secundario da empleo a más del 70\% de los activos.

El sector terciario es el que más empleos proporciona en la provincia, además de encontrarse en período de fuerte crecimiento. Los municipios muy especializados en estas actividades -más del 55\% de sus empleos- son todos litorales, es decir la capital y los turístico-litorales entre Alicante y Calpe. La capitalidad turístico-terciaria de Benidorm queda extraordinariamente destacada, pues son terciarios el 82'1\% de sus activos, lo que le convierte en el núcleo más especializado laboralmente de la región, mientras en la capital de la provincia el sector terciario también alcanza fuerte especialización, el 69'5\% de sus activos, por encima de las otras capitales de la región, pues en Valencia son el 62'7\% y el 57'7\% en Castellón. Tiene especialización terciaria compartida -40 a $54 \%$ de los activos- con otro sector económico, 1) el resto de los municipios litorales, casi todos ellos con función turístico-residencial más o menos pronunciada; 2) Alcoy, con clara vocación de capitalidad para sus comarcas vecinas, y 3) el área metropolitana de Alicante.

Queda patente, pues, la situación de privilegio que goza la ciudad de Alicante como centro jerarquizador para las actividades terciarias especializadas con destino a satisfacer las necesidades de su pujante y densa región urbana, que actualmente se acerca a los 750.000 habitantes (incluidos los de la capital) en un radio de hasta unos $40 \mathrm{~km}$ de recorrido por las carreteras nacionales que confluyen en la capital (V. Gozálvez, 1986).

\section{La estructura por edades y sexo: el inicio de un acusado envejecimiento}

Esta información es de gran interés debido a las diferentes implicaciones demográficas, 
económicas y sociales que tienen los distintos grupos de edades y sexo; interpretar correctamente estos datos es, por tanto, esencial para los estudios de planificación tanto en los relativos a grandes espacios como para los de menores superficies, pues en cualquier caso los usuarios o destinatarios de tales operaciones están primordialmente caracterizados por sus diferentes edades y sexo.

Además, la utilidad científica y práctica de la información contenida en las pirámides de población, o en su caso de subpoblaciones (p.e. población escolar en sus diferentes

grados, población activa en sus diversos sectores, población soltera, etc.), es simultáneamente estática y dinámica. Es decir, por un lado la pirámide nos muestra la situación y posibilidades demográficas de la comunidad en el momento de confeccionar la estadística; por otro, nos informa sobre la historia o evolución demográfica reciente que ha vivido esa comunidad, es decir las fluctuaciones de su natalidad, de su mortalidad, así como los movimientos migratorios de cierta consideración que le han afectado, todo lo cual configura las características de la población en el momento de formar la estadística. Por último, las pirámides de población nos ofrecen utilísimas informaciones para la planificación a corto y medio plazo, es decir en ellas se observa con claridad cuándo las distintas cohortes o grupos de edad van a alcanzar edades que demanden u ofrezcan distintos servicios o actividades, como puestos escolares en sus diferentes niveles, puestos de trabajo, pensiones de jubilación, etc., y también, evidentemente, con qué volumen de población se contará para sustentar las demandas de los grupos de más edad. Naturalmente que todo lo indicado está sujeto a las alteraciones que puedan introducir, en su caso, las migraciones, pues cuanto más reducida o «abierta» sea una comunidad más vulnerable es a modificar su estructura por efecto de las migraciones, incluso a corto plazo y de forma sustancial.

El hecho más llamativo de las pirámides de población más recientes (1986) es, sin duda, el profundo recorte de su base, a resultas de la drástica disminución de nacimientos después de 1977; esta falta de efectivos, si no es reemplazada por inmigración, tendrá efectos sucesivos conforme las generaciones menguadas asciendan en edad, especialmente en aquellas facetas o hechos que afecten a toda la población: por ejemplo en la enseñanza obligatoria, en la demanda laboral, en la demanda de viviendas para nuevos matrimonios, etc.; sin embargo su efecto no será el mismo en actividades o hechos que no afecten a la totalidad de los habitantes de cada comunidad, como por ejemplo en la enseñanza universitaria, ya que puede ocurrir que cuando las generaciones menguadas de la base de la pirámide alcancen los 20 años de edad, la demanda de plazas escolares universitarias se mantenga estable si en esos años crece la proporción de jóvenes que tenga acceso a la Universidad.

El envejecimiento del municipio de Alicante es en 1986 de tipo medio, pues la proporción de habitantes con 65 años o más alcanza al 11'2\% del censo, proporción similar a la del conjunto del País Valenciano y a la de España. Sin embargo, el envejecimiento en Alicante aumentará sustancialmente durante los próximos lustros debido a la suma de varias causas: a) es a partir de 1986 cuando inician la entrada en el grupo viejo las abultadas generaciones que nacieron entre 1920 y 1935, mientras entre 1915 y 1920 se registró una acusada desnatalidad a resultas de los graves problemas económicos-sociales de aquellos años; tal discontinuidad es muy evidente en el perfil de la pirámide de 1986; b) las cohortes que en 1986 están en la antesala del grupo viejo fueron, además, engrosadas por la inmigración que recibió la ciudad entre 1960 y 1970; c) el alargamiento de la vida que llevará a una mayor proporción de personas a franquear los 65 años de edad y, sobre todo, a permanecer más tiempo en esa etapa de edad; d) también aumentará el envejecimiento porque la proporción de población vieja sobre el censo total se verá muy favorecida debido 
a la fortísima disminución del grupo joven, pues no es probable que a corto plazo aumente la natalidad en Alicante, sino que previsiblemente, según los diversos indicadores, aún continuará en descenso; e) por último el envejecimiento de la capital también se verá incrementado por el actual crecimiento de la inmigración de jubilados residentes, que llegan atraídos por las favorables condiciones climáticas locales.

La población de Alicante con menos de 20 años de edad en 1986, ofrece una sucesión de generaciones extraordinariamente brusca, pues entre 1965 y 1975 los nacimientos fueron muy numerosos, mientras que con posterioridad a 1977 han disminuido mucho: en concreto si la población entre 10 y 14 años suma 23.614 habitantes (9'1\% del censo del municipio), los niños de 0 a 4 años son 16.437 o el 6'4\% del censo.

La distribución por edad y sexo de la población de los municipios del área metropolitana de Alicante es sensiblemente paralela a la de la capital, pero con mayor juventud derivada de su funcionamiento como periferia urbana de la capital; no obstante, también muestra tendencia al envejecimiento aunque menor y con evidente retraso respecto a la ciudad central, tal como se observa en la base de la pirámide, así como en la notable diferencia en la población femenina con más de 65 años de edad, más acusada en la capital, que como es norma generalizada atrae a más población con estas características.

\section{Un movimiento natural caracterizado por el descenso reciente de la natalidad y la casi desaparición del crecimiento vegetativo}

El movimiento natural reciente de la capital está caracterizado, igual que ocurre para el conjunto de la nación, por el descenso fuerte y sostenido de los nacimientos entre 1978 y 1987, último año con cifras disponibles: en este período los nacimientos del municipio de Alicante han evolucionado desde 4.883 a 2.938 , es decir han disminuido un $40 \%$, pese a que el censo de población creció un $20 \%$ entre 1975 y 1986. La tasa de natalidad era de 21 '5\% en 1975 y de 11 '4\% en 1986, lo que equivale a una disminución del $47 \%$. En estos mismos años la mortalidad, en cambio, ha permanecido estable, en torno al $8 \%$, con lo que el crecimiento natural ha pasado del 13'7\% en 1975 a sólo 3'8\% en 1986, lo que supone una reducción del 72\%, a consecuencia únicamente del descenso de natalidad.

De acuerdo con lo indicado sobre la evolución esperada en los próximos años, que supondrá un seguro aumento de la tasa de mortalidad por mayor envejecimiento, y un probable mayor descenso de la natalidad, el crecimiento vegetativo a que se llegará en la capital en los próximos años será, pues, nulo o negativo. El previsible descenso de la natalidad es acorde, por una parte, a explicaciones de carácter general, como la restricción voluntaria de los nacimientos especialmente en medio urbano, por motivos culturales en el sentido amplio del término, y por otra a características específicas de esta población urbana; es decir una parte importante del censo de Alicante está formado por población foránea meridional, conocida por su mayor fecundidad y que actualmente disminuye, o al menos tiene paralizado su aumento, mientras sí crece la inmigración desde Madrid y regiones del norte de la península, cuya población tiene tasas de fecundidad más bajas que la media de España (Gozálvez, 1989), y creciente participación de jubilados. También contribuirá a este futuro descenso de nacimientos el mayor envejecimiento esperado a partir de 1986, según se ha analizado al tratar la estructura por edades; asimismo hay que señalar las migraciones de muchos jóvenes matrimonios desde la ciudad central hacia el área metropolitana.

En el área metropolitana de Alicante, el movimiento natural también evoluciona negativamente, aunque con descensos algo menores y tasas actuales más saneadas -saldo vegetativo de 13'4\% en 1975 y de 5'2\% en 1986-; la situación actual se apoya en su estructura por edades más favorable y su mayor dinamismo inmigratorio, tanto para foráneos 
como para jóvenes parejas procedentes de la capital. No obstante, dado el carácter reducido de todo el conjunto del área metropolitana, y la función residencial de que goza el Campello y Sant Joan, las características demográficas del área metropolitana se apartan poco de las de la capital y confluyen a una situación similar.

\section{La población inmigrada en 1986: elevadas tasas y corrientes diferenciadas}

La alta proporción que la población inmigrada ha alcanzado en toda la región urbana que jerarquiza la ciudad de Alicante, es sin duda la característica demográfica más destacable y fundamental, pues la alta participación de los foráneos ha supuesto no sólo un fuerte crecimiento demográfico, sino también un notable rejuvenecimiento de la estructura por edades, que ha sido decisiva para elevar la natalidad y fecundidad. Frente a esta atracción inmigratoria y rejuvenecimiento demográfico operados entre 1960 y 1975, los años 1980 se caracterizan por la casi desaparición de la inmigración meridional y el mantenimiento, o en su caso aparición de corrientes desde el centro y norte de la península, así como desde los países de la Europa Comunitaria, sobre todo los atlánticos.

Según el Padrón de habitantes de 1986, en el municipio de Alicante residen 97.910 habitantes nacidos fuera de la provincia, de los que 24.391 son castellano-manchegos, en su mitad de Albacete, 14.725 andaluces, sobre todo de Granada y Jaén, 14.115 murcianos, 7.790 madrileños, 7.104 castellano-leoneses, 21.598 del resto de regiones españolas y 10.160 son nacidos en el extranjero, aunque sólo 1.993 poseen nacionalidad no española; es decir, los nacidos fuera de la provincia suman el 38\% del censo de la capital, mientras en el resto del área metropolitana estos foráneos alcanzan una presencia similar, el 37\% ó 19.877 en número absoluto. Las cifras indicadas sitúan a Alicante como la capital valenciana relativamente más inmigratoria, pues en la ciudad de Valencia los nacidos fuera de la propia provincia son el $32 \%$ de su censo, el $33 \%$ en el caso de Castellón y el 28\% en Elche.

Además de los extraprovinciales, en la comarca de l'Alacantí residen otros 30.481 inmigrados desde otras comarcas de la provincia de Alicante, de los que 11.020 proceden del Bajo Segura. En total, pues, son 151.000 los inmigrantes extracomarcales empadronados en 1986 en la comarca de l'Alacantí, que representan casi la mitad de su censo.

Las distintas corrientes inmigratorias que recibe la ciudad de Alicante difieren notoriamente de las que se dirigen a su área metropolitana, y sobre todo de las que recibe la vecina Elche. Así en la capital destaca la mayor concentración relativa de los procedentes de Madrid y de las regiones de la mitad norte de España, mientras los andaluces tienen una presencia relativa más alta en el área metropolitana y en Elche. Así los andaluces son el $15 \%$ de los inmigrantes extraprovinciales empadronados en 1986 en la capital, pero suben al $32 \%$ en el área metropolitana de Alicante y al 30\% en Elche. Por el contrario, los inmigrantes desde Madrid, Castilla-León y País Vasco, suman en el municipio de Alicante el 17'3\% de sus inmigrados extraprovinciales, pero en su área metropolitana los de estas procedencias se reducen al 9'6\% y en Elche al 6\%. Desde el punto de vista económico y aplicado es, pues, de interés conocer con cierta profundidad las características de la población inmigrada, pues sólo con indicar las distintas contentes que recibe cada núcleo, ya quedan patentes diferencias sociales importantes en sus poblaciones foráneas, que en nuestro caso subrayan el carácter capitalino de Alicante, al acumular en ella mayor peso relativo la inmigración procedente de las regiones más urbanizadas y de mayor nivel cultural y económico. Sin duda es preciso profundizar en el conocimiento de las características demográficas y socioeconómicas de las diferentes contentes inmigratorias, ya que 


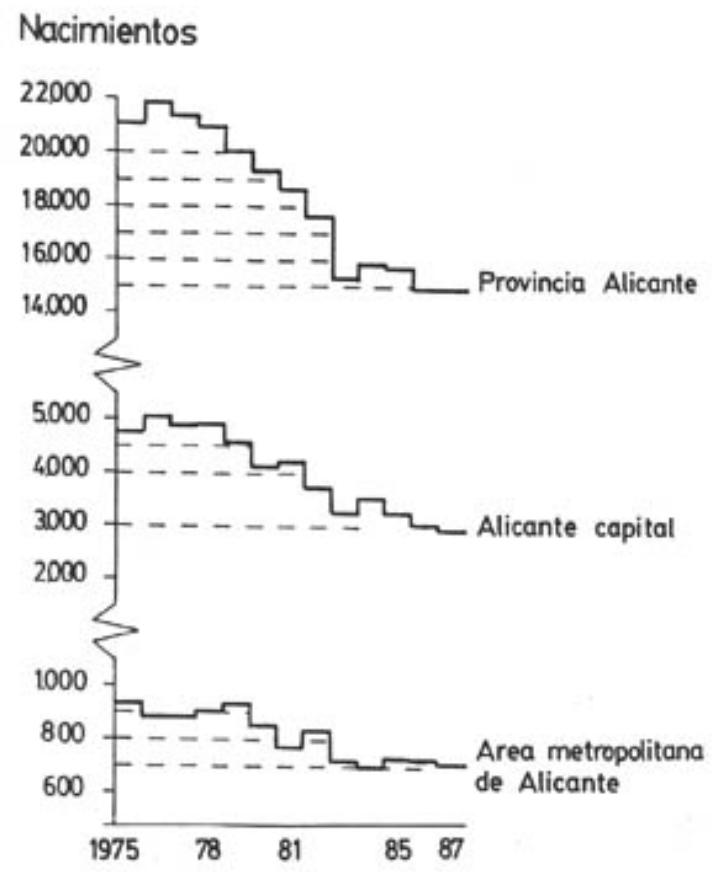

FIGURA 3. Evolución anual del número de nacimientos (1975-1987).

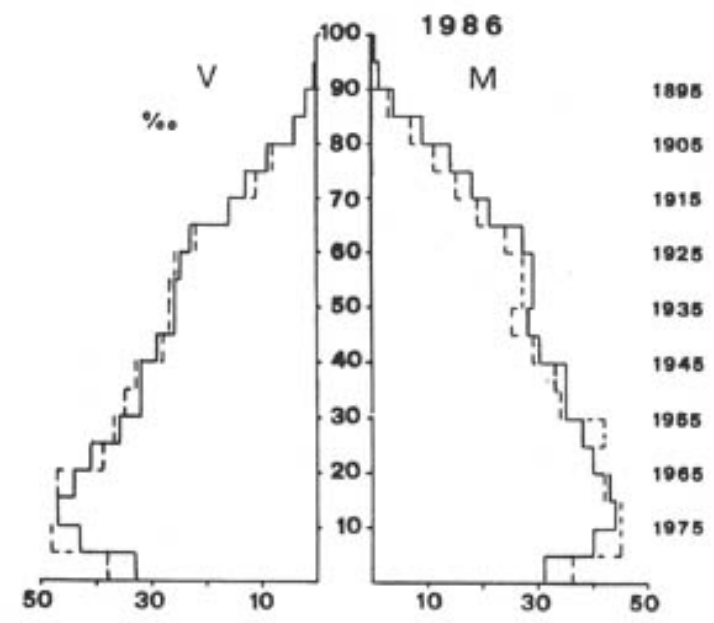

FIGURA 4. Distribución por edad y sexo de la población de Alicante capital (Trazo continuo) y de su área metropolitana (trazo discontinuo). 
todos estos indicadores tienen evidentes repercusiones inmediatas y a medio plazo en los lugares de acogida.

Pese al fuerte incremento relativo en los últimos años de la inmigración urbana desde Madrid y mitad norte de España, la mayoría de los foráneos residentes en Alicante y su comarca proceden de las regiones «especializadas» en el envío de obreros poco cualificados, que es de donde salieron los mayores contingentes, con diferencia, entre 1960 y 1975 . Así, los nacidos en Castilla-La Mancha, Andalucía, Murcia y Extremadura, empadronados en 1986 en la ciudad de Alicante suman 55.416 habitantes o el $57 \%$ de todos sus inmigrados extraprovinciales, mientras en el área metropolitana son 13.867 o el $70 \%$ y en Elche 34.858 o el $72 \%$.

\section{Conclusiones}

Las previsiones sobre el crecimiento demográfico de la ciudad de Alicante, sin duda pueden ser relativamente optimistas. Durante las décadas anteriores, el crecimiento urbano estuvo acelerado por un intenso proceso, en fuerte medida alimentado por un éxodo rural selectivo, compuesto por población joven y adulta-joven, es decir en plena edad laboral y fecunda, que en el caso nuestro procedía mayoritariamente de las regiones más natalistas de la península. En los años 1980, en cambio, se inicia un nuevo modelo de crecimiento urbano en España, que a su vez refleja comportamientos de alcance universal entre los países desarrollados; ahora se aúnan diversos hechos que confluyen en una drástica disminución del crecimiento demográfico de las ciudades, que en mayor o menor medida afectan a la ciudad de Alicante y a su región urbana. Así hay que destacar, a) la crisis económica que provoca gran crecimiento del paro y falta de puestos de trabajo para generaciones de jóvenes muy voluminosas; b) al deterioro de la creación de empleo urbano, se une la degradación de las estructuras demográficas de muchas áreas rurales antes emisoras de población; c) fortísimo descenso de los nacimientos en las ciudades, lo que contrasta con los acusados excedentes naturales originados entre 1960 y 1976 por la inmigración selectiva y el auge económico, y por tanto se aminora sustancialmente el crecimiento demográfico por excedente natural; d) percepción, denuncia y rechazo de los inconvenientes y deterioros medioambientales de las grandes concentraciones urbanas, y que comportan la potenciación de un nuevo modelo de redistribución de la población urbana en poblamiento periurbano y rururbano.

En el caso de Alicante, de su área metropolitana, así como en parte de su región urbana, los factores demográficos negativos para el crecimiento urbano sin duda son actualmente menos acusados que en otras zonas. En este sentido hay que resaltar a) el tamaño aún mediano de la ciudad de Alicante: b) la calidad residencial de la franja costera alicantina, pues pese a sus evidentes deterioros, aún conserva excelentes atractivos por su clima, topografía ondulada y buena accesibilidad; c) no proliferan las industrias de alta contaminación y, además, los centros industriales se localizan fuera de la franja litoral, por lo que el poblamiento rururbano se verá aquí potenciado ante la demanda de residentes europeos atlánticos, de los procedentes de las regiones del centro y norte de España y por parte de los urbanos de la propia provincia de Alicante; d) la importante inmigración meridional llegada aquí entre 1960 y 1975 todavía proporciona un saneado saldo natural, sobre todo en las ciudades industriales como Elche, que con estos aportes foráneos se ha situado durante los últimos lustros a la cabeza de la natalidad valenciana; e) el crecimiento demográfico de la capital y su área metropolitana sin duda recibirá un impulso notable si se confirma una decidida voluntad política y empresarial de potenciar la ciudad como centro de servicios especializados, posibilitados por la previsible demanda de la densa región urbana que jerarquiza la capital, a lo que se ha de sumar el desarrollo de una adecuada diversificación de los sectores de actividad en la capital, incluidas las industrias de alta tecnología, 
compatibles y acordes con el desarrollo económico que se diseña en la actualidad; f) pese a las características positivas indicadas, las previsiones a medio plazo para la estructura demográfica de la capital son de notable envejecimiento, pues la pirámide de edades ya ha recortado fuertemente su «alimento» por la base, que es el que ofrece más resistencia al envejecimiento, mientras las cohortes que en 1986 estaban en el umbral del grupo viejo son muy numerosas; además, durante la presente década la pirámide se alimenta en parte con inmigración envejecida y en parte por sus cohortes de edad media, pero con población urbana procedente de las áreas menos fecundas de España, es decir, la inmigración actual está lejos de ayudar al crecimiento con su excedente natural, tal como ocurrió con la voluminosa inmigración recibida entre 1960 y 1975; g) el crecimiento censal por excedente vegetativo será pues, insignificante a corto plazo, mientras el crecimiento por saldo inmigratorio cuenta con condiciones más favorables, aunque es preciso potenciar la creación de empleo cualificado para que esta inmigración compense, al menos parcialmente, las variadas vías que confluyen hacia el envejecimiento progresivamente acelerado que se prevé para la capital.

Todos los factores positivos para el crecimiento de la ciudad sin duda requieren especiales previsiones y planificaciones, tanto en la potenciación de los sectores económicos más adecuados, como en la organización de unos usos del suelo que en modo alguno deterioren la calidad residencial, cuya trascendencia aumenta mucho en la actualidad, especialmente para los sectores poblacionales que aquí se pretende desarrollar. En este sentido hay que tener presente que las previsiones sobre los movimientos migratorios, tan decisivos sobre los censos urbanos, pueden ser especialmente difíciles y ofrecer tipologías muy variables, ya que aparte de la coyuntura económica general, cada ciudad evoluciona demográficamente según sus características económicas específicas, que son las que mueven a su población activa y en nuestro caso también a un apreciable contingente de residentes no activos que generan cierto volumen de riqueza. Por todo ello, las previsiones sobre la evolución de cada ciudad concreta, requieren un conocimiento preciso de las distintas situaciones y potencialidades locales.

\section{Fuentes y referencias bibliográficas}

CASTELlÓ, E., BADENES, M. A., BERNAT, J. S.: (1988) Crecimiento y crisis en la población valenciana. Valencia, Generalitat Valenciana, $240 \mathrm{pp}$.

Censos de la población de España

Movimiento natural de la población de España.

Generalitat Valenciana. Conselleria d'Economia i Hisenda, Padró municipal d' habitants/1986, 16 vols.

GOZÁLVEZ PÉREZ, V.: (1986) «La región urbana de Alicante», Campus, rev. de la Universidad de Alicante, núm. 8, 1986, pp. 39-44.

GOZÁLVEZ PÉREZ, V. y otros: (1987 a) Atlas sociodemográfico de la ciudad de Alicante, Alicante, Instituto de Estudios «Juan Gil-Albert» de la Diputación Provincial, Ayuntamiento de Alicante, 143 pp.

GOZÁLVEZ PÉREZ, V.: (1987 b) «La población valenciana en 1986: La evidencia de una fuerte y abierta crisis», Cuadernos de Geografía, núm. 42, Valencia, pp. 149-158.

-(1988) «Cambios recientes en la población valenciana» Estudis sobre la població del País Valencià, vol. II, pp. 671-706. Edicions Alfons el Magnànim, Institució Valenciana d'Estudis i Investigació. Institut d'Estudis Juan Gil-Albert. Seminari d'Estudis sobre la Població del País Valencià, 2 vols.

-(1989) «Crise et contrastes spatiaux de la fécondité espagnole», Espace. Populations. Sociétés, núm. 2, pp. 201-214.

-«Els hòmens il'ocupació del territori», ap. Geografia Humana del País Valencià, València, Ed. 3 i 4 (en prensa).

QUIÑONERO FERNÁNDEZ, F.: (1988) Los inmigrados en la ciudad de Alicante, Universidad de Alicante, Ayuntamiento de Alicante, $197 \mathrm{pp}$. 